\title{
DIE KONKRETE EKSPERIMENT, DIE ABSTRAKTE BEGRIP EN DIE STEEDS ONTVLUGTENDE MISTERIE VAN DIE NATUURWETENSKAP.
}

Laat ons uitgaan van die empiries-induktiewe standpunt van die natuurwetenskappe en nagaan hoe natuurwetenskaplike teorieë opgebou word. Wanneer ons dan van die konkrete eksperiment na die abstrakte begrip oorgaan, toon ' $n$ ontleding aan dat die navorser, wat eers seker was, onseker word, en dat die pogings om tot 'n fundamentele teorie te kom teleurstel juis as gevolg van sy eensydige uitgangspunt. Sonder om afbrekende kritiek te lewer wil ons stelselmatig die onhoudbaarheid van die empiries-induktiewe standpunt, as die enigste en selfgenoegsame wetenskaplike metode, aantoon. Die doel wat ons voor oê het is om 'n positiewe gelowige standpunt te skets.

Die natuurwetenskaplike tegniek het sy verbasingwekkendste prestasie met die atoombom behaal. Die "atoom" kan nou "gesplits” word. Die welslae van die natuurwetenskaplike teorie het hierdeur nog aanskouliker getoon waartoe dit instaat is.

Die kontroleerbaarheid van die natuurwetenskaplike teorie het nog altyd as bewys vir sy onomstootlikheid gedien. Slegs wat eksperimenteel kontroleerbaar is dra betekenis: Ons glo nie dat die metodes van suiwere introspeksie, mistieke aanvoeling of loutere intuissie ons enigsins kennis aangaande fisiese verskynsels kan gee nie" 1). Die mening is dat alle ware kennis aangaande die werklikheid slegs aan noukeurige eksperimente te danke is.

Die natuurwetenskaplike metode is dus die kousale metode, 2) waarvan waarneming, eksperiment en induksie die drie belangrike faktore is. Vir die natuurwetenskap is dit die enigste sekere wyse van navorsing. Die natuur kan gedwing word om te antwoord op die vrae wat deur die eksperiment gestel word. Die natuurvorser bou op die vaste fondament van die feite, wat sy eksperimente aan die lig bring. Sodanige feite is vir alle onbevooroordeelde navorsers geldig.

So sterk is die geloof in die onfeilbaarheid van die kousale metode dat daar selfs natuurwetenskaplikes is wat meen dat dit onnodig is om ' $n$ verborge meganisme te veronderstel vir die waargenome verskynsels. Die beeldverklaringe en modelle waarmee Faraday homself bedien deur bv. elektriese en magnetiese velde as kraglyne, waarlangs 'n spanning heers, voor te stel, word afgekeur. Sodanige voorstellinge is nic alleen onnodig nie maar selfs skadelik. 
Navolgers van hierdie standpunt vind steun in die sgn. operasionele gesigspunt van Bridgman, waarvolgens 'n fisiese begrip interpreteer word na aanleiding van die verrigtinge (,operations") wat vir die meting nodig is. Wanneer bv. die ,golflengte" van die sgn. K-lyn van die molibdeen X-straal-spektrum as 0.71 angström aangegee word, dan volg die betekenis daarvan uit die wyse waarop die golflengte gemeet word. Dit word nl. bepaal deur die hoek (thêta te meet in die Bragg-vergelyking, "i-labda $=2$ d. $\sin$ thêta). Hier stel "d" die afstand voor tussen die twee "atoomvlakke" in die ,kristal-traliewerk" van molibdeen, ,(thêta)" die hoek waaronder die X-strale die kristalvlak tref, ,labda" die "golflengte" en "n" is 'n heelgetal. Die begrip ,golflengte" word dus nie alleen op hierdie wyse gemeet nie, maar ook gedefinieer. Wat dit is kan die natuurkundige nie verklaar nie, maar hy is seker dat dit konstant bly.

Dit is egter duidelik dat mens hierdeur nie van die fisiese beeld loskom nie, al word dit ook 'n "term" genoem. In die aangehaalde voorbeeld rus die begrip ,afstand tussen die vlakke in die kristal-traliewerk" op die aanname van die golfteorie vir X-strale. Die fisiese konstante, wat hierbo bepaal is, is tog van ' $n$ beeldverklaring afhanklik.

Sonder sodanige fisiese begrippe val dit te betwyfel of die eksperimenterende natuurwetenskaplike op die fisiese ronstantes sou afgekom het. Talryk is inderdaad die voorbeelde van empiriese wette deur navorsers opgestel, wat deur teoretiese insigte bepaal is. Die konstante verhouding van lading gedeel deur die massa van 'n elektron, is verkry deur die „deeltjie-eienskappe" van 'n „elektron" te veronderstel. 'n Ander voorbeeld word gelewer deur die chemiese kinetika, waar skeikundige navorsers hulle eksperimente op die kinetiese teorie grond. Die beeldverklaring dat reaksiesnelheid bepaal word deur die „effektiewe botsings" tussen die bewegende "molekule," is sowel die leidraad by die opstelling van die eksperimente as dic basis waarop die interpretasie van die resultate berus. Algemeen word dan ook aangeneem dat 'n teorie die weg moet baan tot die ontdekking van nuwe korrelasies tussen die eksperimenteel bepaalbare groothede.

Hierdie gevolgtrekking word deur Darwin soos volg gestel: „Dit is eienaardig dat almal nie insien nie dat alle waarneming voor of teen ' $n$ bepaalde beskouing moet wees om van waarde te wees." 3) Ook Huxley het daarop gewys dat elkeen wat weier om verder as 'n feit te gaan, moeilik sovér as 'n feit kan kom. In die natuurwetenskap is elke groot stap deur 'n intuitiewe insig in die natuur gedoen, d.w.s. deur die toepassing van 'n hipotese wat, hocwel in die begin onbewysbaar en dikwels glad nie maklik bewysbaar nie, tog as leidraad gedien het. 
Hierby sluit die beskouing van Margenau aan, met sy sgn. „construct," waaronder 'n begrip verstaan word 4) wat altyd met 'n bepaalde groep ervaringe vereenselwig word. 'n „Boom” word bv. geassosiëer met sy onderskeie eienskappe van kleur, voorkoms, bodemverankerdheid e.d.m. Netso word 'n „elektron" vereenselwig met verskynsels, wat met sekere gekompliseerde apparate waargeneem kan word: die Wilson-wolkkamer, 'n Geiger-Müller-buis, 'n katode-buis of 'n Millikan olie-druppel. Word die beswaar geopper dat 'n „boom" werklik is, en 'n „elektron” nie, dan word aangevoer dat eersgenoemde ook nie direk gesien word nie, maar dat slegs die lig, wat van die „boom” kom, waargeneem kan word. Die brein word ook nic die lig gewaar nie, maar eerder netvlies-senuprikkels. Die twee begrippe "boom” en „elektron" word dus altwee op indirekte wyse waargeneem, eersgenoemde slegs minder indirek. Die begrip „Boom” is ook vir alledaagse gebruik doeltreffend, terwyl die begrip "elektron" moontlik gewysig sal moet word, of selfs heeltemal elimineer sal word teneinde ' $n$ beter korrelasie tussen bekende feite en moontlike onbekendes, wat in die toekoms ontdek kan word, te bring.

In elk geval is dit duidelik dat waarneming hiervolgens nooit suiwer objektief is nie. 'n Natuurwetenskaplike eis ' $n$ kousale hipotese vir die interpretasie van sy waarnemings. Veral is dit van belang om 'n werkhipotese daarop na te hou wanneer die belangrikheid van 'n bepaalde faktor tussen 'n aantal meewerkende faktore van 'n verskynsel vasgestel moet word.

Die taak van die waarnemer is dus glad nie maklik nie. Dikwels word die hulp van spesiale apparaat ingeroep, waarvan die lesings gekorrigeer en interpreteer word volgens 'n uitgebreide teoretiese sisteem. Verder word die waarnemings statisties geanaliseer om die eksperimentele fout vas te stel.

Op merkwaardige wyse het die natuurkundige Duhem hierdie oorwegings in sy werk "La théorie physique" gestel: 5).

„Gaan 'n laboratorium binne: loop na die tafel waarop 'n verskeidenheid van apparate mekaar verdring -'n elektriese sel, sy-oordekte kopeprdraad, draadspoele, ' $n$ ysterstaaf met 'n spieëltjie; die yster ossilleer en met behulp van die spieëltjie word 'n ligkol op 'n deursigtige skaal gewerp; die heen-en-weer bewegings van die ligkol stel die natuurkundige in staat om die geringste bewegings van die ysterstafie waar te neem. Vra jy hom waarmee is hy besig dan antwoord hy nie: „Ek bestudeer die ossillasies van 'n ysterstaaf,” maar: „Ek bestudeer die elektriese weerstand van spoele." Vra jy hom wat betcken ,elektriese weerstand," dan 
antwoord hy dat jy niks sal verstaan nie alvorens jy die teorie van elektrisiteit nie eers van nader leer ken het nie."

Die waarnemings is dus wel konkreet, maar die gekonstrueerde werklikheid van die natuurvorser is abstrak. Sy werklikheid sluit nie alleen die waarneembare in nie, maar ook die "constructs" van die tans geldige teorie. 6) Hy glo aan 'n "dinamiese" of gekonstrueerde werklikheid. Absolute werklikheid is vir die wetenskap van geen betekenis nie, want daar sal nooit genoeg navorsing gedoen kan word om aan die eis van absoluutheid te voldoen nie. Aan 'n uiteindelike werklikheid word wel geglo omdat die hoop gekoester word dat, namate die teorie meer verfynd word, daar ' $n$ neiging tot konvergensie sal wees.

'n Natuurwetenskaplike teorie gee dus geen werklikheidsinsig nie en kan die verskynsels ook nie verklaar nie. Dit gee hoogstens ' $n$ korrelasie tussen 'n groep verskynsels. 7) Die verbasende prestasies van die natuurwetenskap sterk egter die verwagting dat die voortdurende navorsing uiteindelik die werklikheid sảl blootlê.

Hierdie korrelasie tussen die feite staan i.v.m. twee baie belangrike faktore: taalkundige en wiskundige omskrywing.

Die taalkundige faktor lê daarin dat 'n begrip en sy omskrywing nooit presies dieselfde kan wees nie. 8). Enersyds het ons te doen met taalkundige betekenisse en andersyds met die logiese inhoud van woorde. $\mathrm{Nie}$ alleen veelsinnige betekenisse op taalkundige gebied nie, maar ook veelsinnige begripsvorming bemoeilik die taak van die natuurvorser. Die natuurwetenskaplike noem sy begrippe dikwels „terme," maar in sy geskrewe vorm en in die taalverband wen die term aan sin en inhoud. Hierdie verband is dikwels intultief en onomskrewe. Dit is selfs van 'n ingewikkelde logiese karakter. Ons staan dus voor die feit dat, hoewel die naturwetenskaplike sy begrippe op die vaste grond van die onmiddellik waarneembare bou, hy tog van die taalmedium moet begruik maak en dus onvermydelik voor die moeilikheid te staan kom dat sy begrippe en hulle omskrywing nie identiek is nie.

Die wiskundige faktor staan ook hiermee in verband. Die abstrakte getal leen hom tot ' $n$ cenvoudiger en meer dirckte voorstelling van fisiese groothede. Dit word aangeneem dat die natuurwette ewe eksakt as die wiskunde self die verskynsels moet beskrywe. Vandag word baie diepsinnige wiskundige hoeveelhede soos operators, tensors, matryse, e.d.m., gebruik om teorië op te stel wat met reële waarneminge korreleer. In hicrdie matematiese bewerkinge word materie, die bousteen vir die eksperiment, heeltemal uitgeskakel en al wat oorbly is ingewikkelde wiskundige verbande. Dit is bekend dat in die kwantum-meganika met die 
term „partikel” begin word, teneinde die leser te herinner aan wat die probleem in die klassieke meganika voorstel, maar dat die partikel se eienskappe en die partikel self in die wiskundige bewerking heeltemal elimineer word. 9) Dit tree af en toe weer in die wiskundige bewerking tevoorskyn, maar sonder enige betekenis of funksie behalwe dié wat gepaard gaan met die uitdrukking dat dit êrens is of dat dit 'n sekere mate van momentum besit. Natuurwetenskaplike teorieë het van die vaste materie gegaan na die molekule, van die molekule na verspreide ladings en daarvandaan na waarskynlikheidsgolwe. 10).

Dit word nie algemeen ingesien nie dat die waarskynlikheidsleer, as tak van die wiskunde, net met die abstrakte getal van die wiskunde te doen het en onafhanklik is van ervaring. 11) Die naturwetenskaplike is dan ook versigtig om nie meer inhoud aan sy formules te gee as die betekenis van die formules self nie. So is daar natuurkundiges wat wél die „elektron" as 'n uiteindelike saamstellende deeltjie van 'n onveranderlike werklikheid sien, maar tog die "golffunksie van die elektron" in die kwantum-meganika as 'n formele en nuttige wiskundige greep, sonder reële betekenis, beskou.

Dit is die groot misterie: alles is volmaak onbegrypbaar, maar daar moet tog wél iets agter sit, anders kon die resultate nie so goed gewees het nie. Die imponerende prestasies van die natuurwetenskap is daarvan getuie. Wat sit dan daar agter? lets wat die natuurwetenskaplike nie vermoed nie: sy eie resultate. 12) Die klink paradoksaal. Op 'n verborge wyse beheers die natuurvorser die natuur sonder om dit te deurgrond .

Dit alles draai om die stelling dat die resultaat onafhanklik van natuurwetenskaplike teorie is. Die spektroskopie lewer 'n goeie voorbeeld. Hoe word die elektrone-struktuur om die atoomkern vasgestel? Die natuurkundige verduidelik dat die frekwensies van ligstrale van die gloeiende element gemeet word. In werklikheid word die posisies van lyne op 'n fotografiese plaat gemeet. Hieruit bereken die natuurkundige die frekwensies op die basis van die ooreenstemmende beeldverklaring, wat juis deel is van die teorie van die verskynsels. 13) Daarmee word die wonderbare van die resultate nie verkleineer nie.

Die volgende beeld is meer verklarend. Met behulp van 'n trillende naald word „klank-golwe” op 'n grammofoonplaat opgeneem en by die speel van die plaat word die trillende beweging van die naald deur die gleufies op die plaat weer in „klank-golwe” ongesit. Hierdie vernuftige resultaat is onafhanklik van enige teorie wat ons omtrent die aard van klank saamstel. 
Tog moet daar één teorie wees wat uiteindelik waar moet wees.

Die natuurwetenskaplike teken met sy eksperimente die natuur op sy teorie af en teken met voorspellinge van verskynsele weer van sy teorie af terug. Die noukeurigheid van sy berekenings hang van die noukeurigheid van sy terug-tekening af. Die hoofsaak skyn om berekenings te maak en voorspellinge te kan doen. Die fundamentele natuurwetenskaplike teorie wat ten grondslag van dit alles lê, skyn die navorser steeds te ontvlug. Wat is die grondleggende waarheid? Kan dit bereik word? Hierin lê die groot probleem opgesluit.

Onwillekeurig dink ons aan die woorde van die Prediker: Hy het die ewigheid in die mens se hart gelê sonder dat die mens die werk wat God doen, van begin tot end kan uitvind.

Die strewe is gerig na die volledige, fundamentele natuurwetenskaplike teorie, die waarheid van dit alles. Die denkende mens soek steeds na ' $n$ wêreld- en lewensbeskouing wat die bevindinge van die natuurwetenskap in verband met die geestelike wetenskappe bring. Die waarheid is tog 'n geheel, 'n eenheid. Wetenskaplike arbeid moet dus dien on tot die eenheid van die wetenskap te kom. Tweërlei houding word ingeneem. „Enersyds het ons hulle wat 'n eensydige nadruk lê op die reeks van skitterende ontdekkings van die natuurwetenskappe en hoog hulle lofsang aanhef ter verheerliking van die mens, wat soveel natuurgeheime ontsyfer het. Andersyds het ons diegene, seker in die minderheid, wat hulle oog gevestig hou op die groot gebied wat nog onbekend is en dan moedeloos besluit dat uit die knellende onkunde geen ontsnapping moontlik is nie." 14)

„Teenoor beide rigtings neem die gelowige wetenskaplike stelling in. Hy erken die waarheid in beide beskouings, maar kom tot 'n ander slotsom. Hy aanvaar as uitgangspunt die Skrif, wat nie alleen beperk is tot die eties-religieuse gebied nie, maar ook noodsaaklike elemente bevat, wat betrekking het op die materiële wêreld, waardeur die mens die regte verhouding tussen God, homself en die wêreld leer ken." 8)

Word die vraag gestel op watter wyse die Skrif die gelowige natuurwetenskaplike kan leer dan wys ons allereers daarop dat dit gewigtige gegewens bevat oor die begin en einde van alle dinge,waaroor Maxwell self gesê het: „Science is incompetent to reason upon the creation of matter."

Tweedens word ons navorsing verhef deur die versekering, wat ons andersinds as 'n waarskynlikheid afgelei het uit die wette van ons denkvermoë, dat die heelal 'n geordende geheel is en verstaanbaar is omdat dit die werk is van die hoogste Verstand. Daarom sal die natuurverskynsels 
deur natuurwette beskryf kan word en sal dit reg wees om te sê dat materie optree asof dit uit „atome” en „molekule” bestaan, of dat „elektroniese verskynsels" beskryf kan word deur voorop te stel dat 'n "elektron" onder sekere omstandighede "deeltjie" en onder ander weer "golf-" eienskappe besit. 'n Fisiese begrip word tog nooit werklikheid nie.

Die teoreties gekonstrueerd werklikheid behoort egter met die konkrete werklikheid ooreen te stem. Die ondersoek van die natuur sal ons nooit tot die absolute werklikheid bring nie, want net God is absoluut (en nie ondat daar nooit genoeg navorsing gedoen kan word nie). Vir 'n Christelike natuurwetenskap is dit van grondleggende betekenis. Die natuur, of die feite, het dus nie absolute betekenis nie. Die uitgangspunt dat slegs die kousale metode absolute betekenis het, vernietig weer teoreties die verskeidenheid wat die Skepper in sy handewerk gelê het. Ook hierdie metode het geen absolute betekenis nie. Ons onderskei dus tussen die absolute werklikheid, God, en die geskape werklikheid.

'n Alles omvattende natuurwetenskaplike teorie kan nie tot stand kom nie, omdat ons as eindige wesens die waarheid maar ten dele ken en omdat ons verstand deur die sonde verduisterd is. Uit homself kan die natuurwetenskaplike dus nie tot die eenheid van die waarheid kom nie, maar dit word geopenbaar in die Vleesgeworde Woord: „Ek is die Waarheid." Op die beginsels in Sy Woord en op dic beginsels in Sy Werke moet die Christelike natuurwetenskap gebou word. Die natuurvorser moet die natuur tot die grense van sy kenbaarheid ondersoek en daarna strewe om deur 'n objektiewe deurgronding van die werklikheid die wonder-karakter daarvan bloot te lê: „Want Sy onsigbare dinge kan van die skepping van die wêreld af in sy werke verstaan en duidelik gesien word, naamlik Sy ewige krag en goddelikheid."

Die neutrale natuurwetenskap werk, in die reël, met beginsels sonder om daar rekenskap van te gee: die wesensverskil tussen materie en energie, die selfgenoegsaamheid van die feite, die vervanging van die kousale verband deur 'n funksionele verband, die grense van die wetenskap, die genoegsaamheid van 'n meganiese natuurverklaring e.d.m. Die gelowige natuurwetenskaplike is egter geroepe om van hierdie beginsels deeglik rekenskap te gee. Dieselfde feite moet in 'n eenheid georden word waarin aan Hom die eer gegee word. Geen duimbreed is daar op die wêreld wat nie aan Hom behoort nie.

Juis dáárin lê die taak van die gelowige natuurwetenskaplike. Die Skrif dui die verhewe doel van alle natuurondersoek aan: nie terwille van die wetenskap nie, ook nie terwille van die mens nic, maar aan die Here moet die eer gegee word. 
Word oor die natuurwetenskap só gedink, dan lei sowél die „ons kan nie weet nie” as die „ons sal weet" tot ,aan Hom al die eer." Daardeur verkry natuurwetenskaplike arbeid die ewigheidswaarde wat die pogings van die navorser loon. Daardeur vervul hy sy roeping: die mens moet die natuur onderwerp en daaroor heers.

Potchefstroom, Augustus 1950.

J. A. VAN DEN BERG.

\section{VERWYSINGS:}

(1) G. H. Vinyard, Journ. Chem. Educ. 25, 383 (1949).

(2) H. G. Stoker, "Iets oor Redelikheid en Rasionalisme," J. H. de Bussy, Pretoria (1933)

(3) M. R. Cohen and E. Nagel, "An Introduction to Logic and Scientific Method," Routledge and Kegan Paul, Ltd., London. (1906).

(4) Margenau, Revs. Modern Phys. 13, 176 (1941).

(5) W. F. G. Swann, Revs. Modern Phys. 13, 190 (1941).

(6) A. P. Malan, Koers, VIII, 4, p. 158 (1941).

(7) G van Wageningen, Ongepubliseerde stukke.

(8) J. Bruin, „Het Christelijk Geloof en der Beoefening der Natuurwetenschap," J. H. Kok, N. V. Kampen (1932).

(9) H. G. Stoker, Koers, XVII, I, p. I (1949). 